\title{
BUSINESS MODEL INNOVATION IN THE DIGITAL ECONOMY: BLOCKCHAIN BASED COLLABORATIVE MODELS
}

\author{
Florin PUCHEANU \\ Bucharest University of Economic Studies, Bucharest, Romania \\ florin_pucheanu@yahoo.com \\ Alexandru-Mihai BUGHEANU \\ Bucharest University of Economic Studies, Bucharest, Romania \\ mihai.bugheanu@man.ase.ro \\ Ruxandra DINULESCU \\ Bucharest University of Economic Studies, Bucharest, Romania \\ ruxandra.dinulescu@man.ase.ro
}

\begin{abstract}
The current paper focuses on blockchain technology as a novel actor shaping business models and leveraging another rising star of the global business, collaborative economy.

The research aims to grasp the main intersection points between blockchain drivers and business model components. Therefore, to accomplish this objective, the paper identifies the main impact drivers of blockchain technology in relation to collaborative models as: cost reduction, risk reduction and disinter mediation.

Secondly, we have turned our attention to the methods in which this new technology influences business model innovation.

Furthermore, this paper presents the possible outcome scenarios taking into consideration four stages of business model innovation in relation to different degrees of blockchain adoption by organizations.

The key findings of this study focus on the impact on value proposition, value creation, delivery and value capture, and the ways each scenario constitutes an opportunity or a threat to the focal firm.
\end{abstract}

Keywords: Business model innovation, Blockchain, Digital economy, Digital innovation, Collaborative economy.

\section{INTRODUCTION}

The world is witnessing a technology-based revolution that promises to deeply restructure all the fundaments of the economy and society, bringing new ways of production and distribution for goods and services, and even reshape the way human beings interact with each other. Additionally, this new ultratechnological paradigm is also introducing a new economic system, the collaborative economy. 
With this in mind, traditional organizations, witness their existing way of doing business disrupted by newcomers, which reinvent the logics behind the market transactions, introducing the sharing of goods and services between peers and replacing ownership with access.

Also known as sharing economy, this new phenomenon is characterized by the emergence of new business models, which leverages the communication technology, to build platforms, to facilitate transactions between independent supply and demand market participants. By encouraging and mediating the access to underutilized goods and services (Habibi et al., 2017), these platforms achieve, in theory, a better distribution and coordination of economic practices in the market, while reducing the resource consumption and improving material efficiency.

In general, the novelty of this concept attracted numerous scholars who worked to conceptualize and map the organizing principles and features of the collaborative practices. However, there is a lack of understanding about governing principles in the collaborative economy, and especially drivers that enable and promote genuine sharing practices in the market.

By reviewing the relevant literature on the topic, we have identified two main gaps that we attempt to address in the current paper. The first one is the insufficient conceptualization and exemplification of how collaborative initiatives innovate their business models to create, deliver, and capture value in the market. The second one is the impact the new emerging digital technologies, like blockchain, has on the business model innovation in the collaborative economy.

\section{LITERATURE REVIEW - AN OVERVIEW PRESENTATION OF THE BLOCKCHAIN AND COLLABORATIVE MODELS}

\subsection{Conceptual background - Business model innovation}

Business model innovation is a sub-field of business model analysis, which aims to understand and facilitate the study and planning of evolution from one business model to a better one, and is widely acknowledged as an essential element of strategic management, with key role in generating value across numerous industries.

In fact, scholars generally evaluate business model innovation as either an incremental change of individual parts of the business model or an overall reconfiguration of the entire model, usually as a natural response to challenges and opportunities detected in the market. To put it differently, the ability to implement repeated successful business model innovation is seen as a key driver of resilience for enterprises to cope with changes and constitute a sustainable competitive advantage (Mitchell and Coles, 2003). Based on the literature review, business model innovation is deployed in multiple phases and degrees of complexity, according to the organization's strategy and management approach. 
Furthermore, Mitchell and Coles (2003) conceptualize a framework which depicts business model innovations as a phenomenon comprising four different stages: improvement, catch-up, replacement and actual innovation. As an illustration, we can explain each stage as follows:

- Business model improvement concerns only minor adjustments to a limited number of business model components, keeping the value proposition unchanged. These changes can refer to customer relationships, business infrastructure, or financial aspects, taken in isolation one from another.

- Business model catch-up refers to adjustments taken to keep up the pace with competition and general standards in the market. This requires also minor changes in the value proposition, through introduction of new or improved products and services.

- Business model replacement involves substantial and synchronized changes in a major number of business model elements, without fundamentally modifying the value proposition.

- Business model innovation appears when a redesign of the business philosophies and practices, involving profound changes in all business model landscape, leads to completely new value proposition, through introduction of innovating products or services.

The strategic impact of business model innovation is even more evident now, in light of the technological revolution that unfolds at a scale, scope, and complexity that exceed anything else the human kind has experienced before, and disrupts entire industries, forcing businesses to adapt at an ever increasing speed. For the organizations to successfully adapt and bridge this transition, business model innovation is a vital leverage point because technological innovation alone, seems to yield inferior results. Business model innovations are supposed to generate higher benefits than product or process innovations (Chesbrough, 2007).

\subsection{Conceptual background - Blockchain technology}

First of all, blockchain is a distributed ledger of transactions, based on decentralized nodes, which uses advanced cryptography and consensus mechanisms, to validate and record, in an immutable, secure and verifiable manner, any type of information or exchanges in a network of participants.

Introduced in 2009, with the launch of Bitcoin blockchain infrastructure, this new technology sparked immediate interest from business community, investors, and researchers.

A growing number of research papers focus on the main features and potential advantages of blockchain technology in disrupting market interactions, organization and exchange (Swan, 2015; Beck et al., 2018).

What makes blockchain such an interesting object for investors and researchers alike, is the combination of features and capabilities that incorporates: 
- Immutability enforces a permanent, unalterable network making it impossible to edit, delete or update information after a consensus in the network was reached and the transaction block was included in the ledger.

- Auditability assures the fact that no new transaction is validated until it relates to a previous unspent transaction, through a verification process that solves the double -spending problem (Nakamoto, 2008).

- Digital currency creation refers to the capacity to issue native currency, which can act as a medium of exchange inside the network. Using cryptography, blockchain enables secure and verifiable transactions, and allows for value transfer among participants, in the form of peer-topeer exchange, without the intermediation of private entities, governments or central banks.

- Anonymity enables users to interact with each other and with blockchain infrastructure, without disclosing sensitive information or their identity. Instead, every network participant has a cryptographically issued address, which can use for any matters related to value transfer or information exchange (Swan, 2015).

- Decentralization means that any types of transactions in the network are validated through a consensus mechanism, without the need of a mediating third party to certify data accuracy and enforce trust. Instead, the "truth" is achieved by using different mechanisms like proof-of-work (PoW), or proof-of-stake (PoS), to maintain data consistency and reach a majority backed consensus (Zheng, et al., 2017).

Another important distinction when it comes to blockchain types is the one between public and private network. In a public network, there are no restrictions when it comes to participation, and anyone can see the ledger and take part in the consensus mechanism. A private network is a special type of blockchain technology where only a single organization has authority over the authorization of participation and membership, or in determining the consensus outcome (Zheng et al., 2017). Basically, private entities develop these blockchain platforms for the internal networking and clients' use.

\subsection{Conceptual background - Collaborative economy}

The collaborative economy is the first new economic system to enter onto the world stage since the advent of capitalism and socialism in the early 19th century (Rifkin, 2015), being conceptualized under different forms like "co-production" (Humphreys and Grayson, 2008), "prosumers networks" (Ritzer and Nathan, 2010), "collaborative consumption" (Botsman and Rogers, 2010), peer-to-peer economy, ondemand economy, on-demand services, group economy, independent economy, digital economy.

In fact, collaborative economy is a social and economic framework that fosters the "use of temporary access non-ownership models of utilizing consumer goods and services" (Belk, 2014). This is not a new 
concept in the scientific literature, being conceptualized under different forms, the most well-known being the "product service system".

The novelty element is the generalized use of internet and other cutting edge digital technologies, together with the mass adoption of smartphones to allows for mutualization of exchanges between peers, to create economic value, through new interactions logic, in a hybrid system, a theoretically viable alternative to "pure" capitalism. Leveraged by this new platform-based models, the role of consumers is completely transformed, leading to an "empowerment of ordinary people" (Schor, 2014), turning them from buyers to micro-entrepreneurs, and allowing them to generate alternative income by offering their goods and skills (Dreyer et al.,2017). By allowing for non-monetized models to flourish, the sharing economy is fundamentally altering the relations between people on one hand, and between people and firms in the market, on the other hand.

As stated by Acquier et al. (2017), the sharing economy creates the "opportunity to break through the limitations of centralized economic and political institutions controlled by bureaucracies and professions by harnessing the power of trust, decentralized peer-to-peer networks and markets"

The framework that is widely accepted as the most efficient and flexible organization form for the collaborative economy is the digital technology platforms.

Digital platforms connect independent actors that participate in the market on both, the supply and demand side, and interact with each other to generate value through commercial transactions. The platform does not produce or exchange any goods or services in its property, nor owns any physical infrastructures, other than the online mediating interface. Its role is primordially the one of a mediator, which defines the governance and commercial framework for exchanges and to enable these exchanges through proprietary algorithms.

Thus, the platforms might implement different and gradual models of mediation, from simple facilitator of exchanges to fully assuming control of majority of decision making, this different approach having considerable impact on the business model.

\subsection{Blockchain driven business model innovation for collaborative economy}

This section explores the various ways in which the Blockchain technology influences the dynamics of business model innovation in the collaborative economy.

To introduce and dissect the connections between business model and blockchain main technological drivers, a theoretical business model concept must be presented. In the scientific literature, the concept of business model is closely tied to value, and especially value created for customers (Wirtz, 2011), making distinctions between value proposition, value creation and delivery and value capture. 
In general terms, value proposition refers to products and services offer, the customer segments, and their relationship with the business (Osterwalder and Pigneur, 2010). Value creation and delivery includes the customer value channels, and the value creating structures and activities (Osterwalder and Pigneur, 2010). Also, value capture describes revenue streams used to appropriate economic value from the delivery of goods and services (Teece, 2010).

\section{METHODOLOGY}

In terms of methodology, the survey was implemented in Elsevier and Web of Science Databases, taking into consideration articles in the field of management, with the purpose of reviewing collected and analyzed data and the discussions conducted together with the conclusions and future research. For this purpose, the criteria used are:

1) The content must relate to the concept of Business Model Innovation from a digital perspective.

2) The articles must discuss the impact of Blockchain technology from a managerial perspective and not purely technological studies.

3) The studies should try to explain how the implementation of the Blockchain technology is influencing the Business Models components.

As a reviewing approach, only conference papers and journal articles related to business and management were considered to avoid the technical side of the phenomenon studied. The keywords in the title or abstract search were different combinations and permutations of the following groups: "Business Model Innovation", "Collaborative economy”, "Blockchain technology”, "Digital economy”. The initial working sample contained 127 articles and conference papers. After a preliminary reading of abstract and main ideas and concepts, we have eliminated 108 articles because they were not fitting one or more of the above-mentioned research criteria.

Secondly, by employing the snowball technique, we have added 3 more articles, that the search missed, but their relevance became apparent after reading the list of references in the reviewed papers. In the end, an in-depth literature review was conducted on a total of 22 articles and conference papers. Point often overlooked, a company's main mission in the market, and as a matter of fact, its reason to exist, is managing and creatively combining different sets of resources and partnerships, in order to achieve a double objective: generate value, through goods and services, for customers, while capturing economic value for its shareholders, through revenue stream and infrastructure costs optimizations.

Amit and Zott (2010) emphasize the fact that, activities and resources can be owned by the company and/or acquired from partners. By integrating blockchain technology and leveraging the collaborative capabilities that this is facilitating, the firms might unlock new possibilities of combining activities, skills 
or resources that they neither own or acquire, but gain access to and/or mediate their use, in order to generate value.

As a result, Table 1 depicts possible connections between business model components and blockchain technological drivers.

Analyzing business model components in relation with blockchain main drivers is a valuable tool for decrypting the influence this new technology has on the internal structure and activities of firms which choose to integrate it in their value chain.

TABLE 1. CONNECTIONS BETWEEN BUSINESS MODEL COMPONENTS AND BLOCKCHAIN TECHNOLOGICAL DRIVERS

\begin{tabular}{|c|c|c|c|}
\hline $\begin{array}{l}\text { Blockchain main } \\
\text { value drivers }\end{array}$ & Value proposition & Value creation and delivery & Value capture \\
\hline Immutability & $\begin{array}{l}\text { Better and cost-effective } \\
\text { products due to decreased } \\
\text { and more performant } \\
\text { inventory management. }\end{array}$ & $\begin{array}{l}\text { Achieving safer contracting } \\
\text { relationships with the customers, } \\
\text { through secure, permanent data- } \\
\text { entry. } \\
\text { Clear and secure information flow } \\
\text { inside business network. }\end{array}$ & $\begin{array}{l}\text { Cost reductions } \\
\text { through simplified } \\
\text { and time-effective } \\
\text { information } \\
\text { management. }\end{array}$ \\
\hline Auditability & $\begin{array}{l}\text { Cheaper and better products } \\
\text { and services due to } \\
\text { optimized transactions costs } \\
\text { through uncertainty } \\
\text { reduction. }\end{array}$ & $\begin{array}{l}\text { Fast and efficient customer } \\
\text { transactions and data retrieval. } \\
\text { Transparent transactions and } \\
\text { exchanges between firm and partners }\end{array}$ & $\begin{array}{l}\text { Cost optimization } \\
\text { through increased } \\
\text { auditability of } \\
\text { transactions. }\end{array}$ \\
\hline $\begin{array}{l}\text { Digital currency } \\
\text { creation }\end{array}$ & $\begin{array}{l}\text { New product features and } \\
\text { services, especially fintech } \\
\text { related. }\end{array}$ & $\begin{array}{l}\text { Offering convenient payment } \\
\text { methods for customers at reduced } \\
\text { transaction fees. } \\
\text { Automated transactions between } \\
\text { network participants (through smart } \\
\text { contracts). }\end{array}$ & $\begin{array}{l}\text { Diversified and } \\
\text { dynamic revenue } \\
\text { structure and } \\
\text { increased savings in } \\
\text { financial } \\
\text { transactions. }\end{array}$ \\
\hline Anonimity & $\begin{array}{l}\text { Providing anonymity as a } \\
\text { service for certain customer } \\
\text { segments. }\end{array}$ & $\begin{array}{l}\text { Anonymous customer relationship } \\
\text { possible. } \\
\text { New engagement and governing } \\
\text { types of rules with potential } \\
\text { anonymous participants. }\end{array}$ & $\begin{array}{l}\text { Value capture by } \\
\text { anonymous actors in } \\
\text { the network. }\end{array}$ \\
\hline Decentralization & $\begin{array}{l}\text { Products and services } \\
\text { designed outside of the focal } \\
\text { firm. }\end{array}$ & $\begin{array}{l}\text { Transformed rapports between the } \\
\text { focal firm and co creating customers. } \\
\text { Decentralized processing of } \\
\text { transactions between business } \\
\text { network participants. }\end{array}$ & $\begin{array}{l}\text { Un-intermediated } \\
\text { value distribution } \\
\text { between participants. }\end{array}$ \\
\hline
\end{tabular}




\section{BUSINESS MODEL INNOVATION IN THE DIGITAL ECONOMY: BLOCKCHAIN BASED COLLABORATIVE MODELS}

\subsection{Blockchain driven collaborative economy}

This section emphasizes how blockchain technology alters the dynamics inside the collaborative economy and leverages its impact in the market.

Collaborative economy facilitates value co-creation by enabling the encounter between a resource owner and resource user, to facilitate temporary access to under- utilized goods or services. The collaborative platform's key activity is mediating social and economic interactions (Massa et al., 2017), acting as an infrastructure, as well as a governance entity, enforcing trust between actors, and capturing value through different forms of fees.

Just like the advent of Internet, blockchain could once again, bring major innovations in the development of collaborative practices, enabling ordinary people to be part of a more egalitarian, peer to peer model, which, at least in theory, promises benefits, ranging from reducing costs to better promoting community interest.

The main impact drivers identified in relation to blockchain implementation in collaborative models are:

- Cost reduction: the native blockchain features, promote cost optimization through reduction of transaction uncertainty and information asymmetry, related to documentation, coordination, and information diffusion inside the collaborative network.

Basically, the efficiency and cost effectiveness, are enabled by the implementation of so-called smart contracts, consisting of programming codes which execute different tasks under precise pre-determined condition, without human intervention needed. This feature alone dramatically cuts labor costs and increases efficiency.

- Risk reduction: through secure, permanent data entry. In addition, cryptography, another key feature of blockchain technology, ensures transactions have a built-in verifiable factor, reducing uncertainty, insecurity, and ambiguity (Beck et al., 2016), while protecting at the same time all personal information of network participants or sensitive data.

- Disintermediation: the main feature of blockchain is technology-enabled, real time, secure and immutable networking of transactions, allowing two consenting parties to negotiate directly without resorting to an expensive intermediary.

By reducing the power of intermediaries, blockchain allows users to negotiate directly and transparently with each other when exchanging goods or services, and conclude transactions at a fraction of the costs, fostering new possibilities for accelerated diffusion of collaborative practices in the market. 


\subsection{Blockchain based business model innovation for collaborative economy: opportunities and threats for the focal firm}

Sharing practices offer a wide range of benefits and business opportunities for firms, ranging from cost reduction inside their value networks, to attracting new customers and delivering increased benefits for the existing ones and even image and brand awareness. The main reason "traditional" firms have embraced this new logic of doing business is probably a combination of both benefits and a pressure from new actors in the market, leveraging these practices to disrupt old order and capture value. Murillo et al. (2017), even went that far in suggesting that conservative business models, in this respect, were facing an existential dilemma, when faced with the choice of whether to embrace the sharing practices or not, by stating that this is a "share or die" moment for them.

The collaborative economy flourished into a very dynamic and diverse ecosystem, the technological development leading to an intensification of peer-to-peer exchanges, with traditional firms rethinking their business models to better adapt, and newcomers constantly innovating to try to make their statement in the market.

Nowadays, with the blockchain technology promoting itself as a game changer in the collaborative landscape, firms and platforms are again facing deep transformations of their management and governance systems, internal and external coordination mechanisms, and customer relationship.

In this context, the fact that blockchain technology enables value exchange in the market without intermediary (Pazaitis et al., 2017) and without affecting user confidence (Botsman and Rogers, 2010), puts once again, the centralized collaborative platforms, the winners of the last "disruption game", in face of an even bigger existential dilemma. The dilemma now takes the shape to what extent the adoption and implementation of blockchain technology should go. When it comes to innovation, the different strategies used for leveraging technology to maximize efficiency and productivity enable businesses to gain a competitive advantage and create value (Moreira et al., 2012). But, by rethinking how trust is built between the actors in the market, and how transactions are being conducted in the value network, blockchain technology might prove to be a "trojan horse", with the capacity to disrupt centralized collaborative platforms' business models. Naturally, just like an activity in a firm no longer creating any value is replaced (Prokopenko, 1990), the principle of efficiency dictates the replacing of centralized, value-capturing intermediaries by newly available decentralized platforms, based on blockchain technology.

With this in mind, figure1 depicts four instances of blockchain based business model innovation for collaborative economy, reflected by the different business model innovation stages identified by Mitchell and Coles (2003), in combination with the presumed degree of blockchain adoption by firms and 
platforms, strategies ranging from low to maximum. The circle arcs, graphically represent the boundaries of the focal firm, depicting its capacity to remain relevant in the market, by combining resources and partnerships to generate value proposition, value creation and delivery and to keep the ability to capture value through revenue.

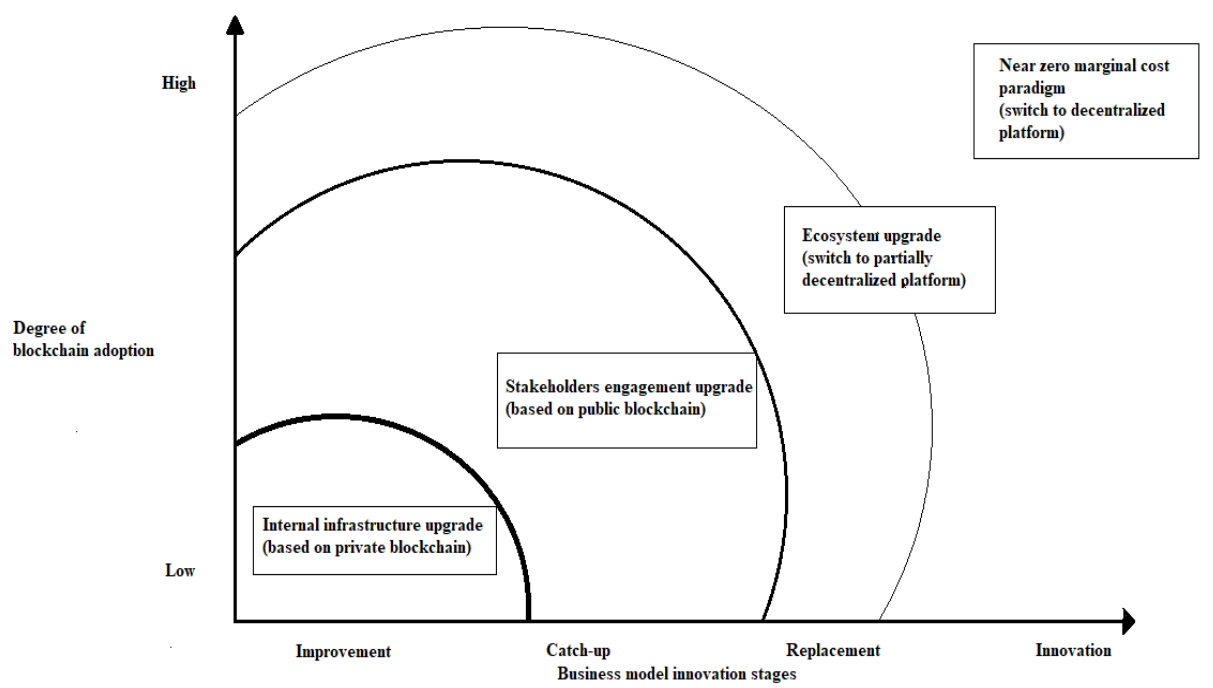

FIGURE 1. BLOCKCHAIN BASED BUSINESS MODEL INNOVATION STAGES

Source: The Authors

\subsubsection{Internal infrastructure upgrade (based on private blockchain)}

This stage represents an incremental innovation in the business model, coupled with low degree of blockchain adoption (one or two features), most likely in the form of private blockchain, intended only for business optimization. This model is introduced to increase efficiency and information flow inside the company, and optimize key activities, while the decision making remains centralized.

In terms of value proposition, this incremental innovation does not change much, products and services offered to customers remaining unchanged. However, due to the novelty of the blockchain operations, some transformations in the customer segmenting and relationship might appear. Value creation and delivery is improved by generating better product traceability in the production stages, together with cheaper logistics management in the value chain.

In effect, value capture improves through cost reductions due to simplified, time and labor efficient internal processes and information flows.

\subsubsection{Stakeholders engagement upgrade (based on public blockchain)}

The next business model innovation might come as a response to competition or market standards pushing for a more attentive consideration and integration of all stakeholders. Consisting of a medium 
degree of blockchain adoption, with more features coming into play, and a catch-up approach to business model innovation, this stage is introducing the public blockchain as a default technology for configuring and managing the value chain.

The value proposition gets improved by redesigning the engagement activities of the customers, more directly involving them in certain processes related to products and services design and review. By decentralizing this activity, the firm also optimizes the customer segmentation process, or even allows customers to auto-coordinate and segment themselves in new and creative ways and react to this much faster as this whole process happens on its blockchain.

In terms of value creation and delivery bringing all stakeholders together on one blockchain, and letting them interact for certain activities, is a recipe for cost reduction, improved efficiency, and productivity.

The value capture comes from increased sales generated by leveraged customer experience and engagement, coupled with cost optimization from increased auditability and efficiency of transactions between organization' stakeholders and partners.

\subsubsection{Ecosystem upgrade (switch to partially decentralized platform model)}

This step represents a radical transformation in terms of business model components, with major rethinking and redesigning of key activities and relationships in the value network. The firm basically switches to a new paradigm in which it creates value, not by producing goods or delivering services for clients, but by facilitating exchanges and interactions inside a newly designed, blockchain based ecosystem. It is nevertheless only a partially decentralized medium, as the focal firm might keep price setting prerogatives and revenue and value capture channels.

The new model in blurring the lines between value proposition and value creation and delivery, as matching exchanges between peers in the network is both the "product" the blockchain owner delivers and the channel through which the network participants deliver value to each other.

In this blockchain based ecosystem, whether it is about business to business (B2B), individual buyers and sellers $(\mathrm{C} 2 \mathrm{C})$, or business to consumers $(\mathrm{B} 2 \mathrm{C})$ interrelations, the main novelty is the overlapping of customer segments; a market participant can simultaneously act as seller and buyer, with the blockchain owner firm "externalizing" basically the value creation process and activities to the ecosystem actors.

As a result of this paradigm switch, new ways of value capturing are also emerging. Together with commission and subscription fees, paid by the ecosystem participants, issuing digital currency for peerto-peer transactions in the blockchain might represent a major revenue stream. Being traded on a global platform and depending on the attractiveness of the blockchain ecosystem for participants to join in, the value of the digital currency can increase exponentially, capturing value for the blockchain owner. 


\section{BUSINESS MODEL INNOVATION IN THE DIGITAL ECONOMY: BLOCKCHAIN BASED COLLABORATIVE MODELS}

\subsubsection{Near zero marginal cost paradigm (decentralized platform model)}

This is a completely new paradigm for the focal firm, imposed from outside by extreme innovations in business model practices in the market, coupled with maximum blockchain adoption in terms of capabilities, leading to a fully decentralized business environment.

Therefore, in the new economic "governance" model, the value proposition, value creation and delivery and value capture, happen outside the focal firm boundaries and do not involve any types of intermediaries in the traditional sense, firms or centralized platforms, but new anonymous mechanisms of governance. In this new, fully digitized economy, where goods and services are no longer exchanged in the market, but shared at near zero marginal cost, between peers on a decentralized, cryptographically organized infrastructure, the "traditional" actors witness their capacity for value capture, and thus, their survival, being put under question.

\section{CONCLUSIONS AND FUTURE RESEARCH}

Considering the literature review and our attempt to contribute to further expanding the understanding of blockchain technology and its interdependencies with business model innovation field and collaborative economy, several interesting directions are taking shape.

First of all, blockchain technology seems to have a big impact on business model components, by enabling new and creative ways of interaction between the focal firm, clients and partners, and offer and demand actors, upgrading the value framework from a simple chain to a more complex, diversified and resilient network model. As a result, value proposition, value creation and delivery and value capture dimensions of the business model can be completely reconfigured, depending on the intensity of blockchain adoption.

Secondly, the intersection between blockchain and collaborative economy turns out to be even more spectacular, with the former leveraging collaborative practices by allowing users to directly engage in transactions with each other and to create and distribute goods, services and information without the mediation of a value capturing intermediary.

On the other hand, some interesting topics for future research have taken shape on the course of the present study. The business governance in the context of blockchain technology adoption needs to be further addressed and conceptualized, together with the notion of trust and novel ways of enforcing it in the value networks.

In conclusion, the main objective objective of this paper was to analyze how the focal firm is influenced by the disruptive levels of decentralization achieved in some scenarios of blockchain adoption. Future research should focus on novel ways in which the firm can adapt its business model to be able to still 
create, distribute and capture value, more like a peer among other peers, instead of an integrator of resources, partners and clients, in a near zero marginal cost paradigm that extreme decentralization promises to unleash.

\section{REFERENCES}

Acquier, A., Daudigeos, T., Pinkse, J. (2017). Promises and paradoxes of the sharing economy: an organizing framework. Technol. Forecast. Soc. Change 125(1): 1-10.

Amit, R., Zott, C. (2010). Business model innovation: creating value in times of change. IESE Working Paper No. WP-870, IESE Business School/University of Navarra, Barcelona.

Beck, R., Müller-Bloch, C., and King, J.L. (2018). Governance in the blockchain economy: A framework and research agenda. Journal of the Association for Information Systems, 19(10): 10201034.

Beck, R., Czepluch, J.S., Lollike, N., and Malone, S. (2016). Blockchain-the gateway to trust-free cryptographic transactions. Proceedings of the 24th European conference on information systems (ECIS), Istanbul, Turkey.

Belk, R. (2014). You are what you can access: Sharing and collaborative consumption online. Journal of Business Research. 67(8): 1595-1600.

Botsman, R., \& Rogers, R. (2010). What's Mine Is Yours: The Rise of Collaborative Consumption. New York, NY: HarperBusiness.

Chesbrough, H. (2007). Business model innovation: it's not just about technology anymore. Strategy\& Leadership. 35(1): 12-17.

Dreyer B., Lüdeke-Freund, F., Hamann, R., and Faccer, K. (2017). Upsides and downsides of the sharing economy: collaborative consumption business models' stakeholder value impacts and their relationship to context. Technological, Forecasting and Social Change. 125(1): 87-104.

Habibi, M. R., Davidson, A. and Laroche, M. (2017). What managers should know about the sharing economy. Business Horizon. 60 (1): 113-121.

Humphreys, A., \& Grayson, K. (2008). The Intersecting Roles of Consumer and Producer: A Critical Perspective on Co-production, Co-creation and Prosumption. Sociology Compass. 2(1): 808-1126.

Massa, L., Tucci, C. L., \& Afuah, A. (2017). A critical assessment of business model research. Academy of Management Annals, 11(1): 73-104.

Mitchell, D., Coles, C. (2003). The ultimate competitive advantage of continuing business model innovation. Journal of Business Strategy. 24(1): 15-21.

Moreira, J., Silva, M., Simoes, J., \& Sousa, G. (2012). Marketing innovation: Study of determinants of innovation in the design and packaging of goods and services application to Portuguese firms. Contemporary Management Research.

Murillo, D., Buckland, H. and Val, E. (2017). When the sharing economy becomes neoliberalism on steroids: Unravelling the controversies. Technological Forecasting and Social Change. 125 (C): 6676.

Nakamoto, S. (2008). Bitcoin: A peer-to-peer electronic Cash system. Satoshi Nakamoto Institute.

Osterwalder, A., Pigneur, Y. (2010). Business Model Generation: A Handbook for Visionaries, Game Changers, and Challengers. John Wiley\&Sons. 
Pazaitis, A., De Filippi, P., \& Kostakis, V. (2017). Blockchain and value systems in the sharing economy: The illustrative case of backfeed. Technological Forecasting and Social Change.

Prokopenko, J., (1990). Gerer la productivite. Geneve, Suisse: Bureau international du travail: Bureau International du Travail.

Richardson, J. (2008). The business model: an integrative framework for strategy execution. Strategic Change. 17(5-6): 133-144.

Rifkin, J. (2015). Welcome to the Third Industrial Revolution. Wharton Magazine.

Ritzer, G., Nathan, J. (2010). Production, Consumption, Presumption the Nature of Capitalism in the Age of the Digital 'Prosumer'. Journal of Consumer Culture. 10(1):13-36.

Schor, J. (2014). Debating the Sharing Economy. Great Transition Initiative.

Swan, M. (2015). Blockchain: Blueprint for a new economy. O'Reilly Media, Sebastopol, CA.

Teece, D.J., (2010). Business models, business strategy and innovation. Long Range Planning. 43(2): 172-194.

Wirtz, B. (2011) Business Model Management Design, Instruments, Success Factors. Gabler, Wiesbaden.

Zheng, Z., Xie, S., Dai, H., Chen, X., and Wang, H. (2017). An overview of blockchain technology: Architecture, consensus, and future trends. 2017 IEEE international congress on big data (BigData congress), 557-564. 